\title{
Application of SimaPro7 on Al-Hilla City Sewerage Network, Iraq
}

\author{
Mohammad Ali Alanbari', Hind Qasim Alazzawi'2, Nadhir Al-Ansariं ${ }^{3}$, Sven Knutsson ${ }^{4}$ \\ ${ }^{1,2}$ College of Engineering, Babylon University, Babylon, Iraq \\ ${ }^{3,4}$ Department of Civil, Environmental and Natural Resources Engineering, Luleå University of Technology, \\ Luleå, Sweden \\ Email: profdr alanbari@yahoo.com, H.Q.Alazzawi@yahoo.com, nadhir.alansari@ltu.se, sven.knutsson@ltu.se
}

Received 15 April 2015; accepted 11 May 2015; published 13 May 2015

Copyright $@ 2015$ by authors and Scientific Research Publishing Inc.

This work is licensed under the Creative Commons Attribution International License (CC BY).

http://creativecommons.org/licenses/by/4.0/

\section{(c) (i) Open Access}

\begin{abstract}
SimaPro is a software package designed to make a valuable contribution for analyzing the environmental impact on products during their whole life cycle. A huge amount of knowledge about the environment is built into the program and database, enabling to analyze a product with a minimum of specialized knowledge. In this study, SimaPro was used to analyze and evaluate the impacts that resulted from sewerage network in Al-Hilla city, Iraq. The results of Life Cycle Assessment (LCA) showed that sewerage network had an impact and damage on the environment by 291 points for every cubic meter of collect wastewater. The most potential environmental impacts were global warming, respiratory inorganics and non-renewable energy, contributing to the sewerage network. The study also showed that most of the effects were as a result of energy consumption in the pumping of wastewater, pipes used and diesel using for network operation.
\end{abstract}

\section{Keywords}

SimaPro, Environmental Impact, Life Cycle Assessment (LCA), Sewerage Network, Al-Hilla, Iraq

\section{Introduction}

Water is a vital natural resource both for humans and for ecosystems and is becoming increasingly scarce owing to increasing demand due to population growth rate and increasing industrial and agricultural activities as well as the effects of climate change. In this context, the provision of a continuous supply of clean water and sanitation to the public is particularly challenging for urban water systems, demanding a sustainable management of the water resource [1]. Sewer network system is a necessary urban infrastructure, playing an important role in the urban areas 
[2]. This includes wastewater collection and its passage through the sewage network to the wastewater treatment plant [3]. Sewer systems include pipe flow, pressure pipes, manholes, discharge nozzles, connections homes, pumping equipment and some facilities that collect and convey water or wastewater to the treatment plant.

Life Cycle Assessment (LCA) is a standard international tool, ISO 14040, used to evaluate the environmental impact of products, processes, and services. It considers the entire life cycle, from raw material extraction to manufacturing, distribution, use, end of life treatment, recycling and eventually disposal [3]. LCA is described in the ISO 14040:1997 series, namely by ISO 14041:1997 standard - definition of objective, scope and inventory analysis, ISO14042:1997 standard —environmental impact assessment, and ISO 14043:1997 standard - interpretation [4]. SimaPro7 software was used for the inventory and database on resources consumption and environmental emissions in the present LCA [5] for Al-Hilla City, Iraq.

\section{Methodology}

\subsection{Sewerage Network}

The case study was sewerage network in AL-Hilla City (Figure 1). Sewerage network in the city consists of 92 $\mathrm{km}$ piping. Types of pipes used in the sewerage network in Al-Hilla city are:

1) UPVC pipes: the length of this type of pipes is $79475.87 \mathrm{~m}$;

2) GRP pipes: the length of this type of pipes is $3210.04 \mathrm{~m}$;

3) Concrete pipes: the length of this type of pipes is $9057.15 \mathrm{~m}$.

\subsection{SimaPro7 Methodology}

SimaPro7 is the computer software tool used to calculate and identify the pertinent environmental impacts associated with the sewerage network in this study. This serves as a tool for managing and storing data, making calculations and sensitivity tests. The LCA phases are structured in SimaPro in accordance with ISO14040 and ISO14044 LCA standards [6].

\subsubsection{Goal and Scope Definition in SimaPro}

A special section is available for description of the goals and scope for each project [5]. In this part, there exist three sub-sections and these include:

Text fields: description of the different aspects of the goals and scope definition can be made. Text entered here can be later copied and pasted into the report. The goals of this study are to analyze and to evaluate the environmental impacts of sewerage network in AL-Hilla City.

Libraries section: it is possible to predefine which library with standard data is considered relevant for the

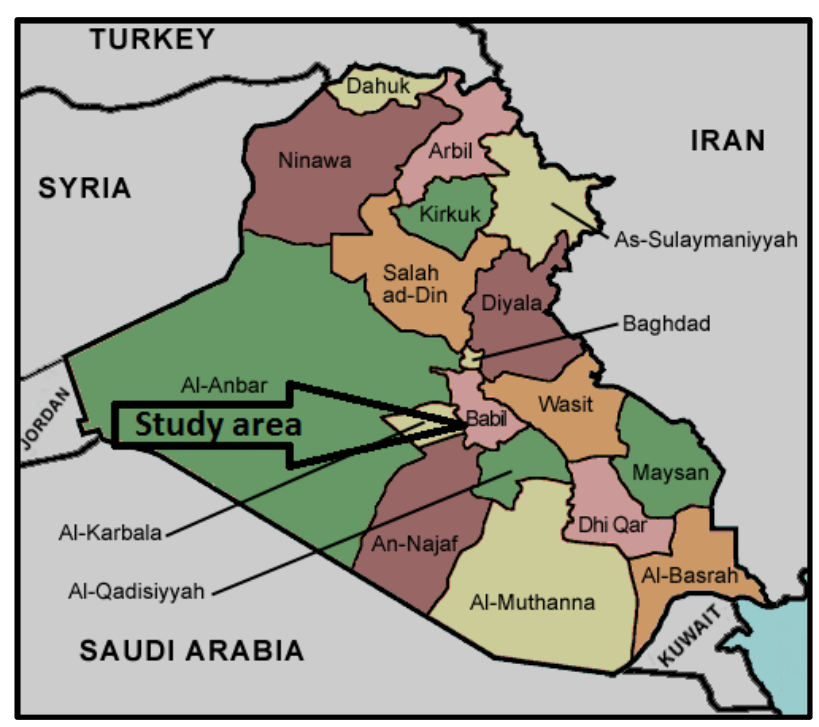

Figure 1. Location of the study area. 
project to be run. In this study, the library of ecoinvent system processes was selected.

Data quality: in this part data characteristics can be predefined.

\subsubsection{Inventory Analysis}

The inventory analysis which involved parameters describing material uses and energy used was quantified in the environmental impacts of 1 cubic meter of collected wastewater. The assessment covers throughout the entire life cycle of the products or activities.

- The unit process: An important goal of data collection is to establish a database which can be used on an ongoing basis for LCA. The data for a process must be collected in form, so called normalizing the process (Figure 2).

\subsubsection{Impact Assessment in SimaPro}

There is wide variety of impact assessment methods available in SimaPro. The basic structure of impact assessment methods in SimaPro is characterization, damage assessment, normalization and weighting. The last three steps are optional according to the ISO standards [6]. In this study, the IMPACT2002+ method was used to determine the environmental impacts of the sewerage network. Figure 3 shows the overall scheme of the IMPACT 2002+ framework, linking all types of LCI results via the 14 midpoint categories (human toxicity, respiratory effects, ionizing radiation, ozone layer depletion, photochemical oxidation, aquatic ecotoxicity, terrestrial ecotoxicity, terrestrial acidification/nitrification, aquatic acidification, aquatic eutrophication, land occupation, global warming, non-renewable energy and mineral extraction) to the damage categories (human health, ecosystem quality, climate change and resources) [7].

\subsubsection{Interpretations in SimaPro}

This is designed as a checklist which covers the relevant issues mentioned in the ISO standards used. As suggested by [5], observations are filled in when the LCA study is about to be completed and conclusions made.

\section{Results and Discussion}

The results of LCA were mostly not straight forward in favour of material design over the alternative one. Results of LCA had to be interpreted or weighted. The IMPACT2002+ methodology and LCA weighting method specially developed for product design was used. This method had proved to be a powerful tool for designers to aggregate LCA results into easily understandable and user-friendly numbers or units, the so called IMPACT 2002-IMPact Assessment of Chemical Toxics.

Figure 4 shows the global eco-score damage in terms of impact categories on studied sewerage network. It is

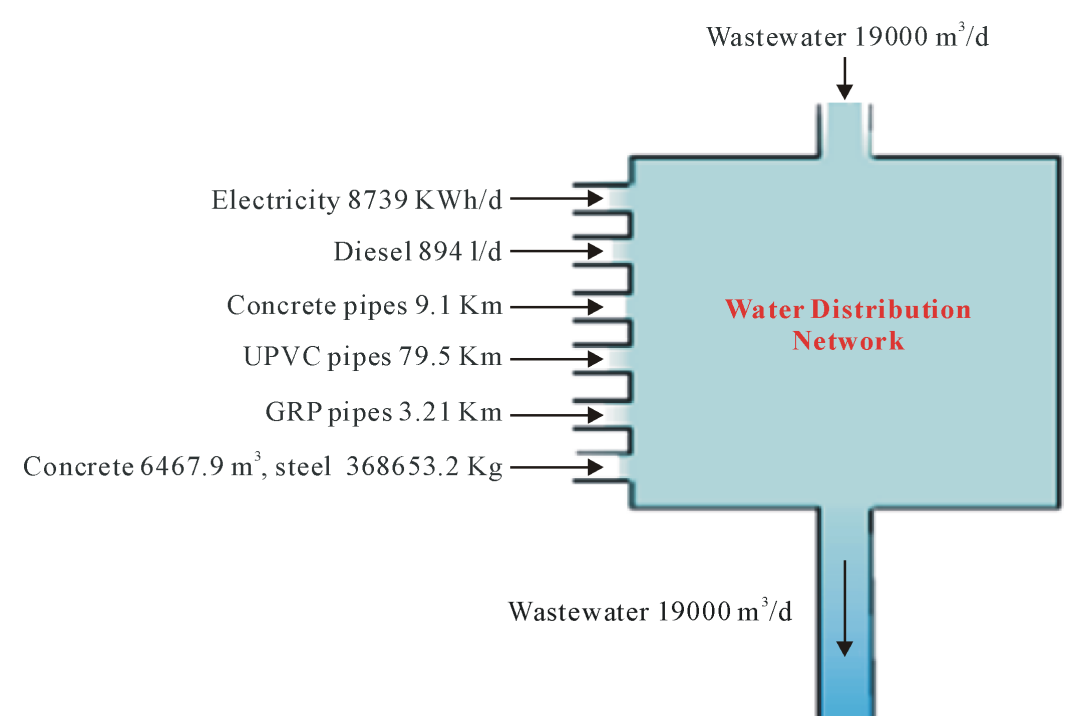

Figure 2. Inventory analysis of sewerage network. 


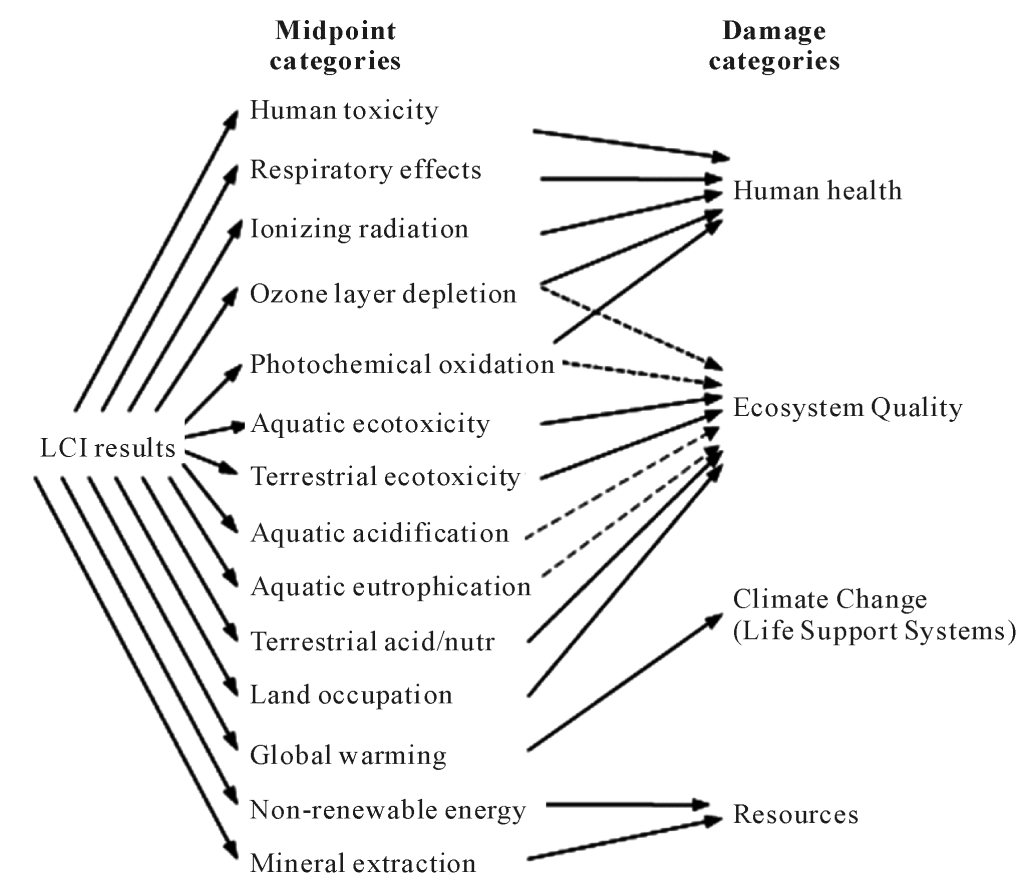

Figure 3. Overall scheme of the IMPACT 2002+ framework, linking LCI results via the midpoint categories to damage categories [7].

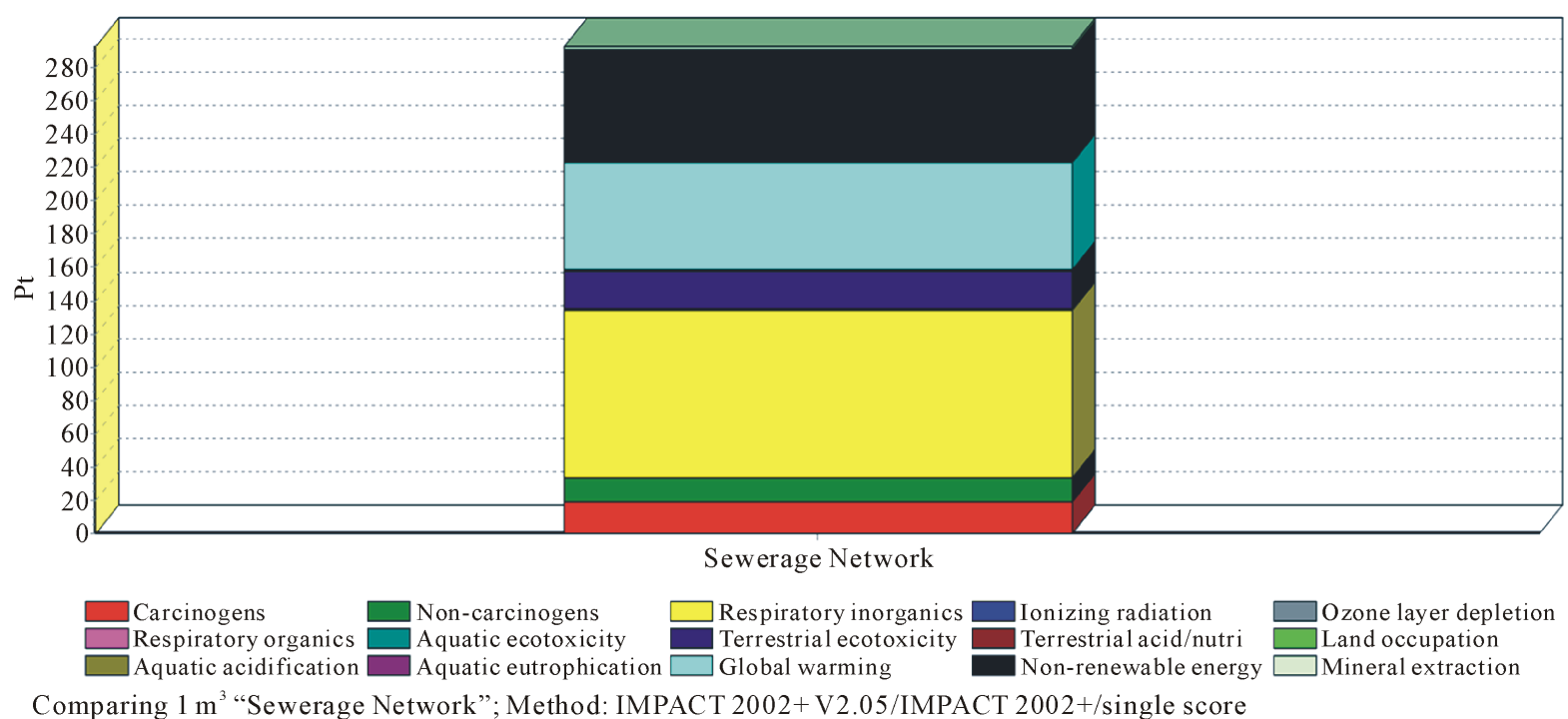

Figure 4. Global eco-score of damage in terms of impact categories.

noted that the most environmental impacts potential are global warming, respiratory inorganic and non-renewable energy, contributing to the sewerage network. In sewerage network, global warming, respiratory inorganic and non-renewable energy contributed $64.38,100.4$ and 67.40 points respectively of total impact of 289 points.

The damage categories were also analyzed by IMPACT 2002+. Four categories of damage were pointed out: human health, ecosystem quality, climate change and resources (Figure 5). From Figure 5, it can be shown that the environmental damage on human health, resources and climate change are much more important than the damage on ecosystem quality. In sewerage network, the total damage contributed was 292 points. It can be identified that the contributions of different variables were: 134.3 points to human health, 24.68 points to ecosystem quality, 64.38 points to climate change and 69.35 points to resources. 


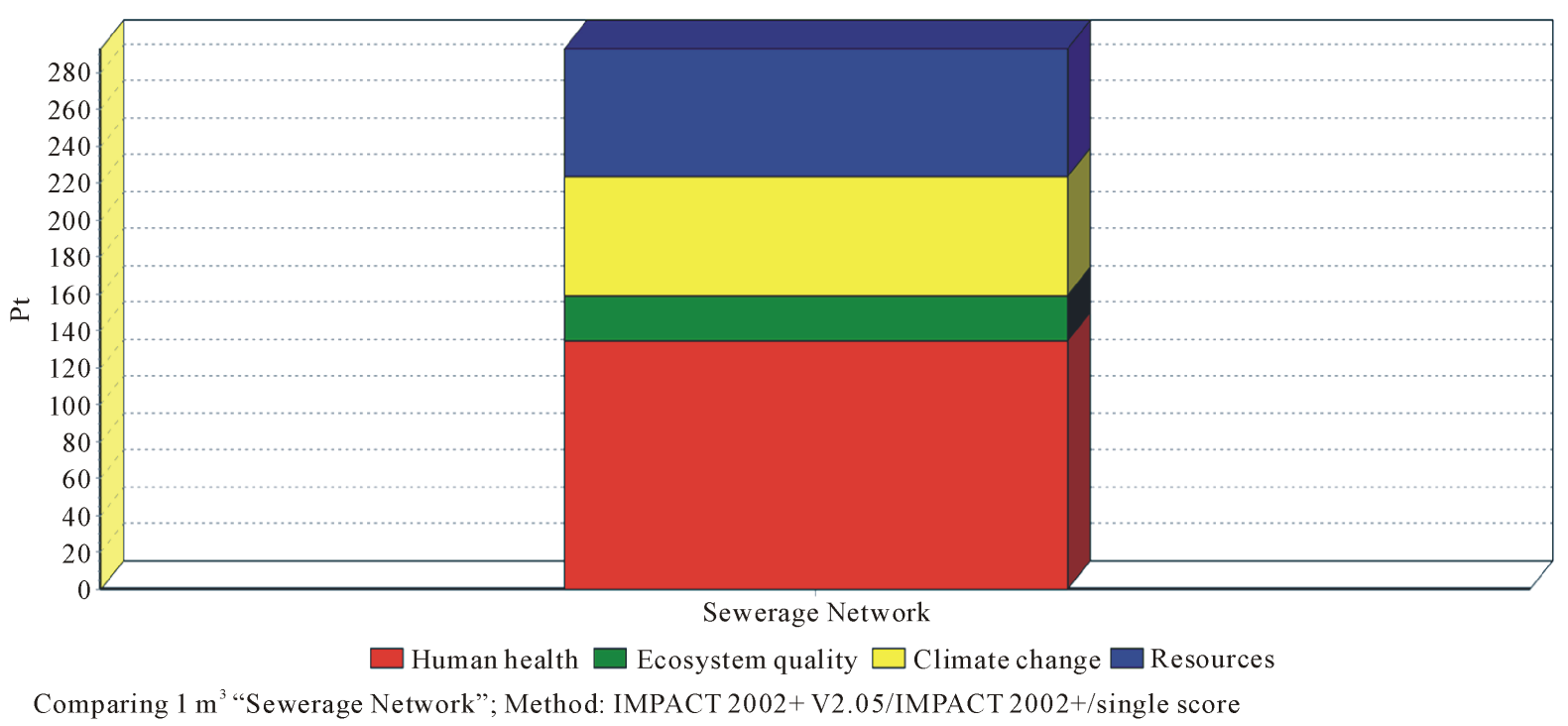

Figure 5. Global eco-score of damage categories.

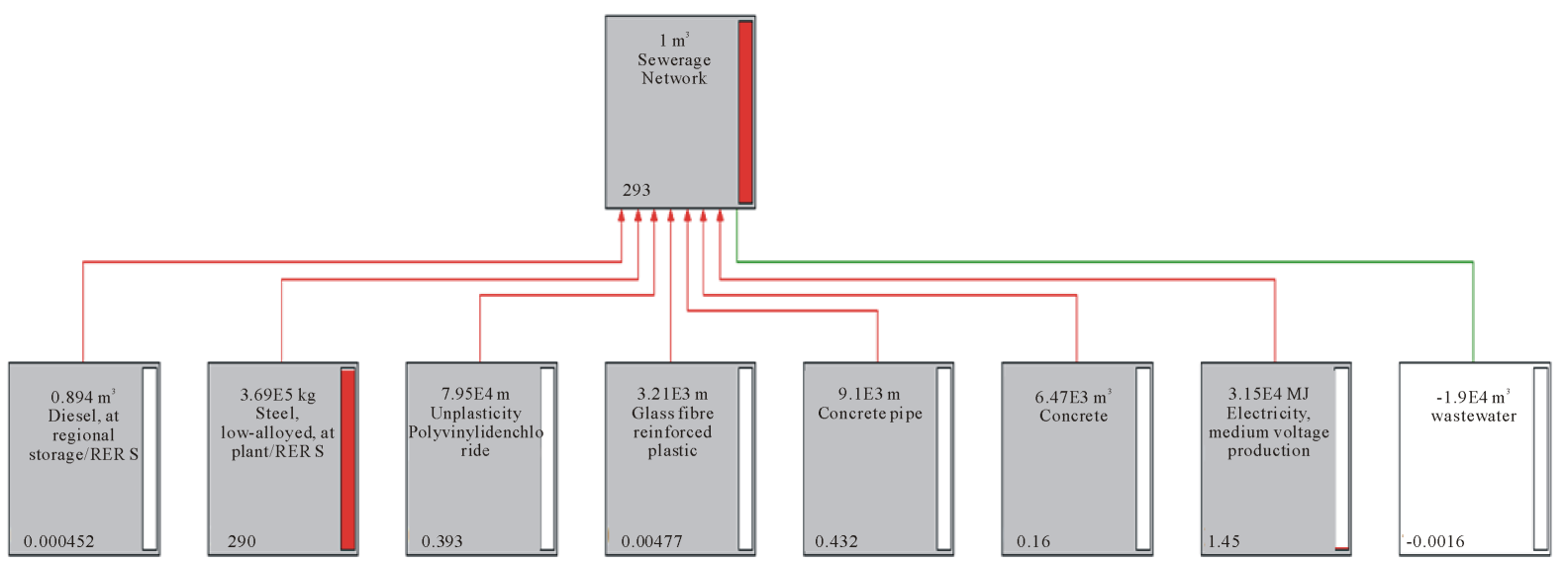

Figure 6. Processes contributions of sewerage network.

It should be noted that steel is one of the most processes that contribute several negative effects to the environment, followed by electricity, concrete pipes, UPVC pipes, reinforced concrete, GRP pipes and then diesel. Wastewater has positive effects, as described in Figure 6. The negative sign in this figure refers to that the indicator has positive effects on the environment.

\section{Conclusions}

The IMPACT2002+ method is one of methods in SimaPro7. It was applied to evaluate environmental indicators for sewerage network in AL-Hilla City. As a result, the following conclusions were noticed:

- The global eco-score on the distribution network was 291 points;

- The most potential environmental impacts were global warming, respiratory inorganic, non-renewable energy and non-carcinogens as a result of electricity consumption, pumping wastewater, pipes used, and diesel using for network operation. In sewerage network, global warming, respiratory inorganic and non-renewable energy contributed $64.38,100.4$ and 67.40 points respectively of total impact (289 points);

- Environmental damage effects on the human health, resources and climate change are relatively much more important than the damage on ecosystem quality. In sewerage network, the total damage contributed was 292 points. It can be identified that 134.3 points contributed to human health, 24.68 points to ecosystem quality, 64.38 points to climate change and 69.35 points to resources. 


\section{References}

[1] Lemos, D., Dias, A.C., Gabarrell, X. and Arroja, L. (2013) Environmental Assessment of an Urban Water System. Journal of Cleaner Production, 54, 157-165. http://dx.doi.org/10.1016/j.jclepro.2013.04.029

[2] Jang, S., Roesner, L. and Park, D. (2006) Development of Urban Storm Sewer Optimal Layout Design Model Considering Risk. World Environmental and Water Resource Congress, Omaha, 21-25 May 2006, 1-10.

[3] Amores, M.J., Meneses, M., Pasqualino, J., Antón, A. and Castells, F. (2013) Environmental Assessment of Urban Water Cycle on Mediterranean Conditions by LCA Approach. Journal of Cleaner Production, 43, 84-92. http://dx.doi.org/10.1016/j.jclepro.2012.12.033

[4] Altaee, S.A. (2013) Comparison Study for Appraisals of Environmental Sustainability Indicators Wastewater Treatment Plants for Middle Euphrates Region in Iraq. M.Sc. Thesis, College Engineering, University of Babylon, Babylon.

[5] PRé Consultants (2013) Introduction to LCA with SimaPro. www.pre-sustainability.com/download/SimaPro8IntroductionToLCA.pdf

[6] Akwo, N.S. (2008) A Life Cycle Assessment of Sewage Sludge Treatment Options. M.Sc. Thesis, Aalborg University, Aalborg.

[7] Frischknecht, R. and Jungbluth, N., Eds. (2007) Implementation of Life Cycle Assessment Methods. Swiss Centre for Life Cycle Inventories, Dubendorf. http://www.pre-sustainability.com/download/manuals/EcoinventOverviewAndMethodology.pdf 